\title{
Neuroprotection by the Endogenous Cannabinoid Anandamide and Arvanil against In Vivo Excitotoxicity in the Rat: Role of Vanilloid Receptors and Lipoxygenases
}

\author{
W. B. Veldhuis, ${ }^{1,2 \star}$ M. van der Stelt, ${ }^{3 \star}$ M. W. Wadman, ${ }^{3}$ G. van Zadelhoff, ${ }^{3}$ M. Maccarrone, ${ }^{4}$ F. Fezza, ${ }^{5}$ G. A. Veldink, ${ }^{3}$ \\ J. F. G. Vliegenthart, ${ }^{3}$ P. R. Bär, ${ }^{2}$ K. Nicolay, ${ }^{1}$ and V. Di Marzo ${ }^{5}$ \\ ${ }^{1}$ Department of Experimental In Vivo Nuclear Magnetic Resonance, Image Sciences Institute, and 2Department of Experimental Neurology, University \\ Medical Center Utrecht, 3584 CX, Utrecht, The Netherlands, ${ }^{3}$ Department of Bio-Organic Chemistry, Bijvoet Center for Biomolecular Research, Utrecht \\ University, $3584 \mathrm{CH}$, Utrecht, The Netherlands, ${ }^{4}$ Department of Biomedical Sciences, University of Teramo, 64100 Teramo, Italy, and ${ }^{5}$ Endocannabinoid \\ Research Group, Istituto di Chimica Biomolecolare, Consiglio Nazionale delle Ricerche, 80078 Pozzuoli, Naples, Italy
}

Type 1 vanilloid receptors $\left(\mathrm{VR}_{1}\right)$ have been identified recently in the brain, in which they serve as yet primarily undetermined purposes. The endocannabinoid anandamide (AEA) and some of its oxidative metabolites are ligands for $\mathrm{VR}_{1}$, and AEA has been shown to afford protection against ouabain-induced in vivo excitotoxicity, in a manner that is only in part dependent on the type 1 cannabinoid $\left(\mathrm{CB}_{1}\right)$ receptor. In the present study, we assessed whether $\mathrm{VR}_{1}$ is involved in neuroprotection by AEA and by arvanil, a hydrolysis-stable AEA analog that is a ligand for both $\mathrm{VR}_{1}$ and $\mathrm{CB}_{1}$. Furthermore, we assessed the putative involvement of lipoxygenase metabolites of AEA in conveying neuroprotection. Using HPLC and gas chromatography/mass spectroscopy, we demonstrated that rat brain and blood cells converted AEA into 12-hydroxy- $\mathrm{N}$-arachidoylethanolamine (12-HAEA) and 15-hydroxy- $\mathrm{N}$-arachidonoylethanolamine (15-HAEA) and that this conversion was blocked by addition of the lipoxygenase inhibitor nordihydroguaiaretic acid. Using magnetic resonance imaging we show the following: (1) pretreatment with the reduced 12-lipoxygenase metabolite of AEA, 12-HAEA, attenuated cytotoxic edema formation in a $\mathrm{CB}_{1}$ receptor-independent manner in the acute phase after intracranial injection of the $\mathrm{Na}^{+} / \mathrm{K}^{+}-\mathrm{ATPase}$ inhibitor ouabain; (2) the reduced 15-lipoxygenase metabolite, 15-HAEA, enhanced the neuroprotective effect of AEA in the acute phase; (3) modulation of $\mathrm{VR}_{1}$, as tested using arvanil, the $\mathrm{VR}_{1}$ agonist capsaicin, and the antagonist capsazepine, leads to neuroprotective effects in this model, and arvanil is a potent neuroprotectant, acting at both $\mathrm{CB}_{1}$ and $\mathrm{VR}_{1}$; and (4) the in vivo neuroprotective effects of $\mathrm{AEA}$ are mediated by $\mathrm{CB}_{1}$ but not by lipoxygenase metabolites or $\mathrm{VR}_{1}$.

Key words: arvanil; anandamide; cannabinoid; vanilloid; CNS; excitotoxicity; ouabain; neuroprotection; neurodegeneration

\section{Introduction}

The eicosanoid anandamide $[N$-arachidonoylethanolamine (AEA)] mimics the pharmacological actions of $\Delta^{9}$-tetrahydrocannabinol (THC), the main psychoactive compound in marijuana, and was the first endocannabinoid to be discovered (Devane et al., 1992) (for review, see Di Marzo et al., 1998). THC, AEA, and the other endocannabinoid 2-arachidonoylglycerol (Mechoulam et al., 1995) exert neuroprotection in several models of neuronal injury (Nagayama et al., 1999; Panikashvili et al., 2001; van der Stelt et al., 2001a,b) (for review, see Mechoulam et

\footnotetext{
Received Jan. 21, 2003; revised March 6, 2003; accepted March 6, 2003.

W.B.V. is financially supported by the Netherlands Organisation for Scientific Research, Medical Sciences Council. V.D.M. is partly supported by Ministero per I'Universita' e Ricerca Scientifica e Tecnologica Grant 3933 and Volkswagen Stiftung. We are indebted to C. Berkers for expert technical assistance. Sanofi Recherche is gratefully acknowledged for the gift of SR141716A.

*W.B.V. and M.v.d.S. contributed equally to this work.

Correspondence should be addressed to either of the following: G. A. Veldink, Department of Bio-organic Chemistry, Bijvoet Center for Biomolecular Research, Padualaan 8, Utrecht University, 3584 CH, Utrecht, The Netherlands, E-mail: g.a.veldink@chem.uu.nl; or V. Di Marzo, Endocannabinoid Research Group, Istituto di Chimica BiomolecoIare, Consiglio Nazionale delle Ricerche, Via Campi Flegrei 34, Ex Comprensorio Olivetti, Fabbricato 70, 80078 Pozzuoli, Naples, Italy, E-mail: vdimarzo@icmib.na.cnr.it.

M. van der Stelt's present address: Endocannabinoid Research Group, Istituto di Chimica Biomolecolare, 80078 Pozzuoli, Naples, Italy.

Copyright $\odot 2003$ Society for Neuroscience $\quad 0270-6474 / 03 / 234127-07 \$ 15.00 / 0$
}

al., 2002), and mice with a defective type 1 cannabinoid $\left(\mathrm{CB}_{1}\right)$ receptor gene appear to be more susceptible to injury after stroke (Parmentier-Batteur et al., 2002). At variance with the protection observed with AEA in the late phase (7 d) after induction of excitotoxicity (van der Stelt et al., 2001b) and unlike the effect of THC (van der Stelt et al., 2001a), the protection afforded by the endocannabinoid in the early phase $(15 \mathrm{~min})$ was not sensitive to the $\mathrm{CB}_{1}$ receptor antagonist SR141716A. This suggests that AEA or its metabolites may convey neuroprotection via other molecular targets in addition to the $\mathrm{CB}_{1}$ receptor. Indeed, both AEA and 2-arachidonoylglycerol exert, in vitro, neuroprotective effects that are not always attenuated by a cannabinoid $\mathrm{CB}_{1}$ antagonist (Sinor et al., 2000).

AEA is also a full agonist at the type 1 vanilloid receptor $\left(\mathrm{VR}_{1}\right)$ (Zygmunt et al., 1999; Smart et al., 2000), which is the target of capsaicin, the pungent principle in hot chili peppers. The $\mathrm{VR}_{1}$ is a nonselective cation channel expressed in sensory fibers, in which it acts as a ligand-, proton-, and heat-activated integrator of nociceptive stimuli (Szallasi and Blumberg, 1999) and whose presence in the brain has been also established (Mezey et al., 2000; Sanchez et al., 2001; Szabo et al., 2002). Because, in the CNS, VR is unlikely to be gated by noxious heat and low $\mathrm{pH}$ as in the peripheral nervous system, endogenous ligands for this receptor, 
such as AEA, $N$-arachidonoyldopamine (Huang et al., 2002), and lipoxygenase products of both arachidonic acid (AA) (Hwang et al., 2000) and AEA (Craib et al., 2001) might exist in the brain. These compounds, once produced under inflammatory conditions, might activate $\mathrm{VR}_{1}$ with subsequent calcium influx (Szallasi and Blumberg, 1999), glutamate release (Marinelli et al., 2002), and substantial contribution to neuronal excitotoxicity. Conversely, exogenous compounds capable of quickly desensitizing $\mathrm{VR}_{1}$, such as many $\mathrm{VR}_{1}$ agonists, including $\mathrm{AEA}$, might exert neuroprotective actions by preventing $\mathrm{VR}_{1}$ activation by endogenous stimuli, and this mechanism might underlie the previously reported anticonvulsant effect of capsaicin (Dib and Falchi, 1996).

In the current study, we investigated the role of $\mathrm{VR}_{1}$ and lipoxygenase products in the neuroprotection elicited in vivo by AEA. To this aim, we assessed the following: (1) the formation of lipoxygenase metabolites of AEA in rat blood and brain; (2) their effects in our in vivo model of neurodegeneration; (3) the effect of $\mathrm{VR}_{1}$ stimulation using capsaicin and arvanil, a "hybrid" $\mathrm{VR}_{1} / \mathrm{CB}_{1}$ agonist; and (4) the effects of the $\mathrm{VR}_{1}$ antagonist capsazepine and of the lipoxygenase inhibitor nordihydroguaiaretic acid (NDGA) on AEA-induced neuroprotection.

\section{Materials and Methods}

Brain tissue preparation. Male Wistar (200-300 gm) rats were killed by an overdose of pentobarbital and decapitated, after which their forebrains were rapidly isolated. Blood was collected in PBS containing $\mathrm{Na}_{3}$-citrate $(0.15 \mathrm{M})$. Some of the animals were transcardially perfused with PBS. Brains were minced with a razor blade and collected in ice-cold PBS (10 gm of tissue/100 $\mathrm{ml}$ of PBS).

Anandamide incubations. Brain tissue or blood cells were preincubated at $37^{\circ} \mathrm{C}$ for $10 \mathrm{~min}$ before a $20 \mathrm{~min}$ incubation with ionophore $\mathrm{A} 23187$ $(10 \mu \mathrm{M}), \mathrm{Ca}^{2+}(1 \mathrm{mM})$, and $40 \mu \mathrm{M}$ substrate. In the case of AEA, $100 \mu \mathrm{M}$ PMSF was included in the incubation mixture. Reaction was terminated by addition of precooled chloroform/methanol (2:1) to extract lipids according to the Bligh and Dyer method (Bligh and Dyer, 1959).

HPLC analysis and product identification. Reversed-phase HPLC chromatograms were obtained using a Hewlett-Packard (Palo Alto, CA) HP1090 liquid chromatograph equipped with an HP1040A diode array detector with a detection limit $<40 \mathrm{pmol}$ (for conjugated dienes) and with an HP79994A analytical workstation. HPLC nalysis was performed on a Cosmosil 5C18-AR $(5 \mathrm{~mm}$; $250 \times 4 \mathrm{~mm}$ inner diameter; Nacalai Tesque, Kyoto, Japan) column, using a methanol/water mixture (80:20) as the eluent at a flow rate of $1 \mathrm{ml} / \mathrm{min}$. Compounds were collected and dried under $\mathrm{N}_{2}$ flow and silylated with a bis(trimethylsilyl)fluoroacetamide for $15 \mathrm{~min}$ at room temperature. Gas liquid chromatography/ mass spectroscopy (GC/MS) analysis was performed by injecting the samples on column (25 m HT-5 SGE column, $0.1 \mathrm{~mm}$ film thickness; SGE, Austin, TX). The column temperature was held at $70^{\circ} \mathrm{C}$ for $3 \mathrm{~min}$ and then allowed to rise $240^{\circ} \mathrm{C}$ at $40^{\circ} \mathrm{C} / \mathrm{min}$, followed by an increase of $16^{\circ} \mathrm{C} / \mathrm{min}$ up to $330^{\circ} \mathrm{C}$. Mass spectrometry was performed with a Fisons Instruments MD 800 mass detector. Mass spectra were recorded under electron impact with an ionization energy of $70 \mathrm{eV}$.

Animal model. Neonatal Wistar rats (U:Wu/Cpb; 7-8 d old) were anesthetized with ether and immobilized in a stereotaxic frame. A small burr hole was drilled in the cranium over the left hemisphere, $2.5 \mathrm{~mm}$ lateral of bregma. A $1 \mu \mathrm{l}$ syringe was lowered into the left striatum to a depth of $4.0 \mathrm{~mm}$. Ouabain $(0.5 \mu \mathrm{l}, 1 \mathrm{~mm}$; Sigma-Aldrich, Zwijndrecht, The Netherlands) was injected at a rate of $0.125 \mu \mathrm{l} / \mathrm{min}$ using a microdrive. After injection, the needle was left in situ for $2 \mathrm{~min}$ to avoid leakage of injection fluid from the needle tract. Body temperature was maintained at $37^{\circ} \mathrm{C}$ using a water-filled heating pad and an infrared heating lamp. Animals, needed for magnetic resonance imaging (MRI) study, were then positioned in the magnet, and anesthesia was continued using a mixture of halothane $(0.4-1 \%)$ in $\mathrm{N}_{2} \mathrm{O}-\mathrm{O}_{2}$.

Pharmacological treatments. Arvanil was synthesized as described previously (Melck et al., 1999). 12-Hydroxy- $N$-arachidoylethanolamine
(12-HAEA) and 15-hydroxy- $N$-arachidonoylethanolamine (15-HAEA) were synthesized, purified, and characterized as described previously (van Zadelhoff et al., 1998). AEA was obtained from Biomol (Heerhugowaard, The Netherlands), SR141716A from Sanofi Recherche (Montpellier, France), capsaicin and capsazepine from Tocris (Köln, Germany), and NDGA from Sigma-Aldrich. Animals used in the MRI study were treated intraperitoneally with arvanil $(0.1 \mathrm{or} 1 \mathrm{mg} / \mathrm{kg} ; n=5$ and $n=6$, respectively), arvanil ( $1 \mathrm{mg} / \mathrm{kg}$ ) plus SR141716A (1 and 3 $\mathrm{mg} / \mathrm{kg} ; n=5$ and $n=4$, respectively), arvanil ( $1 \mathrm{mg} / \mathrm{kg}$ ) plus capsazepine ( 5 and $10 \mathrm{mg} / \mathrm{kg} ; n=4$ and 10 , respectively), capsaicin $(1 \mathrm{mg} / \mathrm{kg} ; n=5)$, AEA $(1 \mathrm{mg} / \mathrm{kg})$ plus $15-\operatorname{HAEA}(7 \mathrm{mg} / \mathrm{kg} ; n=7)$, NDGA $(10 \mathrm{mg} / \mathrm{kg} ; n=$ 6) $5 \mathrm{~min}$ before AEA (10 mg/kg), NDGA (10 mg/kg; $n=6)$, AEA (10 $\mathrm{mg} / \mathrm{kg})$ plus capsazepine $(10 \mathrm{mg} / \mathrm{kg} ; n=5)$, capsazepine $(10 \mathrm{mg} / \mathrm{kg} ; n=$ $5), 12$-HAEA ( $3 \mathrm{mg} / \mathrm{kg} ; n=6)$, or 12-HAEA ( $3 \mathrm{mg} / \mathrm{kg}$ ) plus SR141716A $(3 \mathrm{mg} / \mathrm{kg} ; n=5)$. Control animals received vehicle alone $(n=16)$. 15-HEAE was tested at a dose likely to produce a molar ratio with AEA (7:1) similar to the one previously found in vitro to inhibit AEA degradation (van der Stelt et al., 2002b). Because 12-HAEA and 15-HAEA are only very weak agonists at $\mathrm{VR}_{1}$ and 15 -HAEA is only a weak ligand at $\mathrm{CB}_{1}$, we did not test the effect of capsazepine on the two compounds, nor of SR141716A on 15-HAEA or of 15-HAEA alone (Hwang et al., 2000; van der Stelt et al., 2002b). Because AEA is a very weak functional agonist at $\mathrm{CB}_{2}$ receptors (Bayewitch et al., 1995; Gonsiorek et al., 2000) and arvanil has little if any affinity for these receptors (Melck et al., 1999; Di Marzo et al., 2002), no experiment with $\mathrm{CB}_{2}$ antagonists were performed. All drugs were dissolved in $1 \mathrm{ml} / \mathrm{kg}$ body weight 18:1:1 v/v PBS/Tween 80/ethanol, $30 \mathrm{~min}$ before toxin injection. There was no difference in body weight and growth rate between any of the groups. The Utrecht University Animal Experiment Ethical Committee approved all protocols.

MRI experiments. MRI was performed on a $4.7 \mathrm{~T}$ Varian horizontal bore spectrometer. Resonance frequency excitation and signal detection were accomplished by means of a Helmholtz volume coil $(9 \mathrm{~cm}$ diameter) and an inductively coupled surface coil ( $2 \mathrm{~cm}$ diameter), respectively. A single-scan diffusion-trace MRI-sequence [four $b$ values, 100-1300 $\mathrm{sec} / \mathrm{mm}^{2}$; repetition time (TR), $3 \mathrm{sec}$; echo time (TE), $100 \mathrm{msec}$ ] was used to generate quantified images of tissue water trace apparent diffusion coefficient. Diffusion-trace- and $\mathrm{T}_{2}$-weighted imaging (TE of 18, 40, 62, and $84 \mathrm{msec}$; TR of $2 \mathrm{sec}$; number of transients, 2) were performed in all animals $(2.2 \times 2.2 \mathrm{~cm}$ field of view; $64 \times 64$ data matrix $)$, starting at $t=$ $15 \mathrm{~min}$ after injection on day 0 and were repeated 1 week later. As expected, at this early time point, no changes in $\mathrm{T}_{2}$-weighted MRI were detected. Both the $\mathrm{T}_{2}$-weighted and the diffusion-weighted (DW) datasets consisted of seven consecutive 1.5 -mm-thick slices, with $0 \mathrm{~mm}$ slice gap. To minimize interference at the slice boundaries, slices were acquired in alternating order $(1,3,5,7,2,4,6)$, thus maximizing the time between excitation of two neighboring slices. For the diffusion-weighted imaging, we used a double spin-echo pulse sequence with four pairs of bipolar gradients with specific predetermined signs in each of the three orthogonal directions as published recently (De Graaf et al., 2001). The combination of gradient directions leads to cancellation of all offdiagonal tensor elements, thus effectively measuring the trace of the diffusion tensor. This provides unambiguous and rotationally invariant apparent diffusion coefficient (ADC) values in one experiment, circumventing the need for three separate experiments. For each $b$ value, two scans were averaged. The total scan time for acquisition of seven slices, with four $b$ values and two averages, was $17 \mathrm{~min}$.

Data analysis. $\mathrm{ADC}$ and $\mathrm{T}_{2}$ maps were generated by monoexponential fitting using the Interactive Data Language software package. Parametric images were analyzed in anatomic regions of interest using the Interactive Data Language software package. Pixels in the ipsilateral hemisphere were considered pathological if their $\mathrm{ADC}$ or $\mathrm{T}_{2}$ value differed more than twice the $\mathrm{SD}$ of the mean value in the contralateral hemisphere. The ventricles were segmented out in the average $\mathrm{ADC}$ and $\mathrm{T}_{2}$ measurements. The lesion volume per slice was calculated by multiplying the lesion area (number of pathological pixels $\times$ field-of-view in $\mathrm{cm}^{2} /$ number of points acquired per image) by the slice thickness. The total lesion volume was obtained by summation of the lesion volumes for all slices. The absence of a slice gap makes interpolation of lesion areas between slices unneces- 


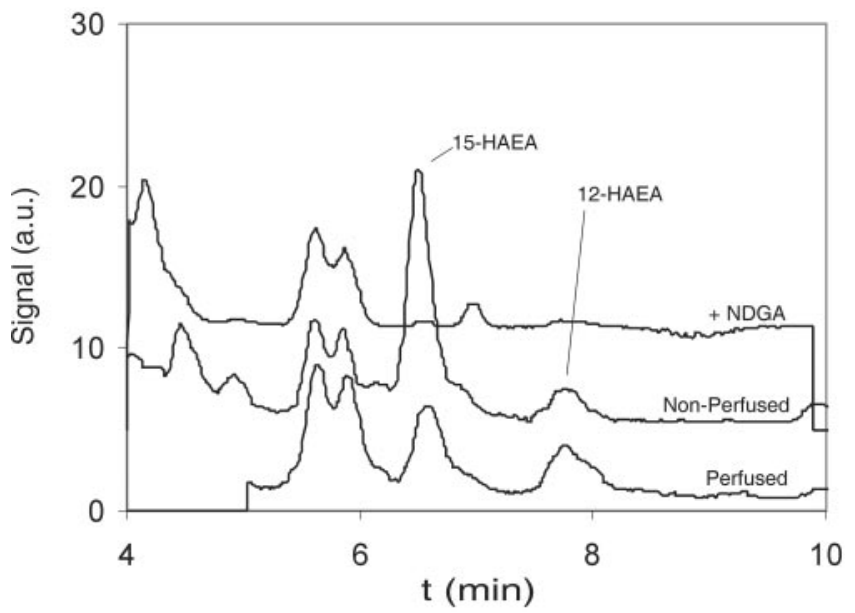

Figure 1. Reversed-phase HPLC profiles $(\lambda=236 \mathrm{~nm}$ ) of lipid extracts of anandamide incubations with rat brain homogenates using a C18-column with methanol/water (80:20 v/v) as eluent. Top trace, Anandamide incubation with rat brain and NDGA, a nonselective lipoxygenase inhibitor. Middle trace, Anandamide incubation with nonperfused rat brain. Bottom trace, Anandamide incubation with PBS perfused rat brain. a.u., Arbitrary units.

sary, reducing systematic errors to within-slice "averaging" of signal intensity. Statistical analysis was performed using SPSS 10.0 (SPSS, Chicago, IL). Differences between groups were analyzed using Student's $t$ test; reported $p$ values correspond to two-tailed significance.

\section{Results}

Lipoxygenase metabolism of anandamide

Reversed-phase HPLC analyses of the lipid extracts of AEA incubations with rat brain homogenates were performed to determine whether AEA metabolites were formed. The reversed-phase HPLC analyses revealed that several products eluted with an absorption at $\lambda=236 \mathrm{~nm}$, which were absent in control incubations without AEA. These peaks were not present when NDGA, a nonselective lipoxygenase inhibitor, was included in the incubation (Fig. 1). Two peaks eluted at the same retention times as the reduced lipoxygenase products of AEA, 15-HAEA (TR of 6.4 min) and 12-HAEA (TR of $7.9 \mathrm{~min}$ ), respectively. The UV spectra of these materials demonstrated an absorption maximum at 236 $\mathrm{nm}$ and were similar to the spectra of standards of 12-HAEA and 15-HAEA. The peaks were collected, derivatized, and subjected to GC/MS analysis. The mass spectra confirmed that the peaks eluting at 6.4 and 7.9 min represented 15-HAEA and 12-HAEA, respectively. AEA incubations with brains from rats that were transcardially perfused with PBS before dissection demonstrated a similar elution profile, although the ratio of 15-HAEA to 12HAEA was changed (Fig. 1). This suggested that at least a part of the oxygenated metabolites, especially 15-HAEA, were produced by lipoxygenases expressed in blood cells. AEA incubations with rat blood cells demonstrated that 15-HAEA and 12-HAEA could be formed (data not shown). The cellular origin of the lipoxygenase activity was not investigated.

\section{Role of lipoxygenase metabolites in neuroprotection after anandamide treatment}

We wanted to investigate whether the lipoxygenase metabolites of AEA detected here might mediate the non- $\mathrm{CB}_{1}$-mediated acute neuroprotective effect of AEA in our rat model of in vivo excitotoxicity (van der Stelt et al., 2001b; Veldhuis et al., 2003). In these experiments, we used reduced lipoxygenase products of AEA because the hydroperoxy derivatives will be rapidly degraded in vivo. In our model, excitotoxicity is induced by phar-
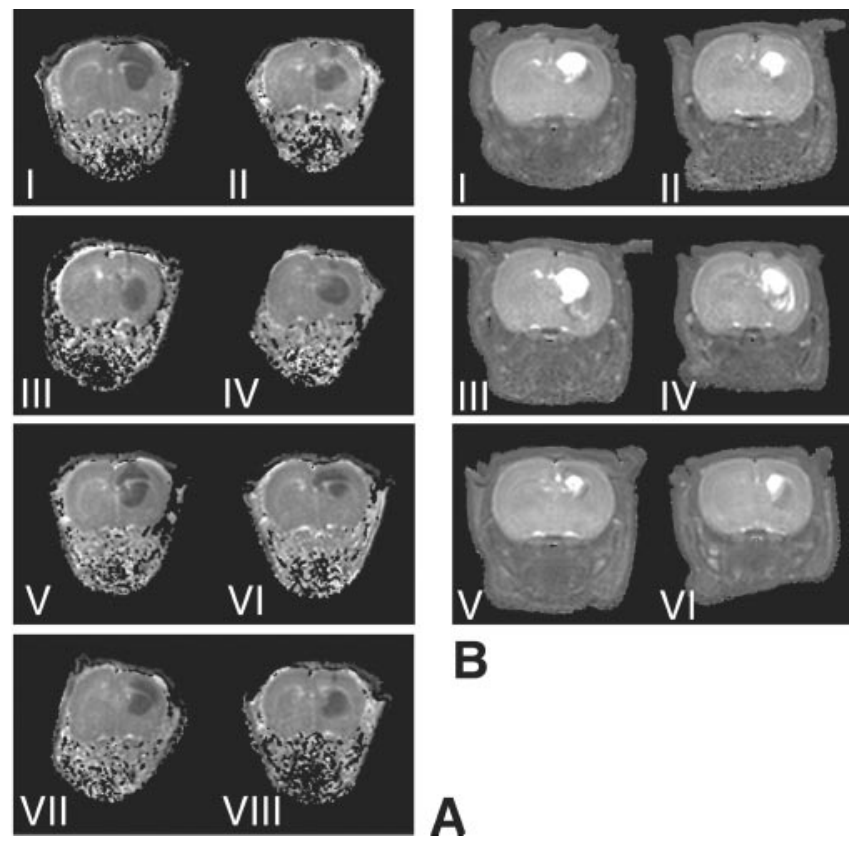

B

Figure 2. A, Typical parametric $A D C$ maps of rat brain, calculated from diffusion-weighted MRI data acquired 15 min after ouabain injection. $B$, Parametric $\mathrm{T}_{2}$ maps of the corresponding slices of the same animals, calculated from $\mathrm{T}_{2}$-weighted MRI data acquired 1 week later. The treatments are as follows: I, vehicle; II, AEA (1 mg/kg) plus 15-HAEA; III, 12-HAEA; IV, 12-HAEA plus SR141716A; V, capsazepine; VI, AEA (10 mg/kg) plus capsazepine; VII, NDGA; and VIII, AEA (10 mg/kg) plus NDGA.

macologically inhibiting the $\mathrm{Na}^{+} / \mathrm{K}^{+}$-ATPase using ouabain. The resulting acute cellular swelling (i.e., cytotoxic edema) is conveniently monitored using diffusion-weighted MRI. ADC maps of tissue water, calculated from DW-MRI datasets, showed hypointense regions with reduced ADC values $(0.64 \pm 0.006 \times$ $10^{-3} \mathrm{~mm}^{2} / \mathrm{sec}$ ) in the ipsilateral hemisphere of all animals. In the contralateral hemisphere, normal ADC values $(1.13 \pm 0.01 \times$ $10^{-3} \mathrm{~mm}^{2} / \mathrm{sec}$ ) were measured (Fig. $2 \mathrm{~A}$ ). We showed previously that administration of AEA itself dose-dependently reduces lesion volume in this model (van der Stelt et al., 2001b). The reduced 12-lipoxygenase metabolite of AEA, 12-HAEA, attenuated the volume of cytotoxic edematous tissue in the acute phase after injection of ouabain $(p<0.05)$ (Figs. $2 A, 3)$. The $\mathrm{CB}_{1}$ antagonist SR141716A was unable to block this effect, indicating that the $\mathrm{CB}_{1}$ receptor was not involved in the protection afforded by 12 HAEA (Figs. 2A, 3). The reduced 15-lipoxygenase metabolite of AEA, 15-HAEA [which was shown previously to be only a weak ligand at $\mathrm{CB}_{1}$ but to inhibit the enzymatic hydrolysis of AEA (van der Stelt et al., 2002b)], enhanced the protection afforded by a low dose $\left(1 \mathrm{mg} / \mathrm{kg}\right.$ ) of AEA [from $37.2 \mathrm{~mm}^{3}$ (van der Stelt et al., $2001 \mathrm{~b}$ ) to $26.6 \mathrm{~mm}^{3}$ ( $p<0.05$ ); (Figs. $2 \mathrm{~A}, 3$ )]. $\mathrm{T}_{2}$ maps calculated from $\mathrm{T}_{2}$-weighted images acquired $7 \mathrm{~d}$ later showed normal $\mathrm{T}_{2}$ values $(71.9 \pm 0.04 \mathrm{msec})$ in the contralateral hemisphere of all animals. The ouabain-injected hemisphere showed hypointensities and hyperintensities (Fig. $2 \mathrm{~B}$ ). Both types of $\mathrm{T}_{2}$ abnormalities indicate pathological change. Hyperintensities correlate to regions of vasogenic edema and tissue loss, whereas hypointensities correspond to regions displaying reactive gliosis (Veldhuis et al., 2003). Calculation of total lesion volumes based on both hyperintensities and hypointensities indicated that neither the protection afforded by 12-HAEA nor the effect of 15HAEA lasted until day 7 (Figs. $2 \mathrm{~B}, 3$ ). The dose of 12-HAEA tested significantly reduced lesion volume in the acute phase, 

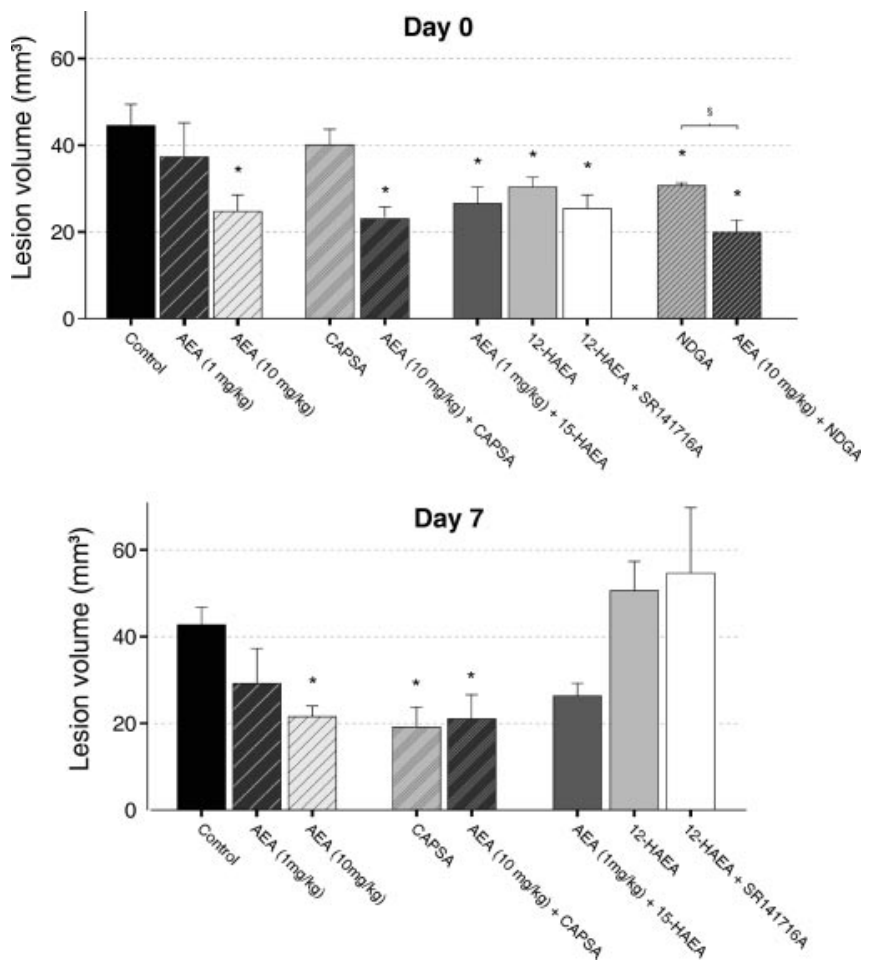

Figure 3. Lesion volumes as determined from $A D C$ maps on day 0 and $T_{2}$ maps on day 7 . The effects of several combinations of $A E A, A E A$ metabolites, $C_{1}$ and $V R_{1}$ antagonists, and a lipoxygenase inhibitor on lesion volume are shown. For comparison, the effect of AEA alone is also shown. This effect was determined in a previous study (van der Stelt et al., 2001b). Error bars represent means \pm SE. ${ }^{*} p<0.05$ versus control; $\S p<0.05$ for AEA plus NDGA versus AEA alone. See legend to Figure 2 for all of the doses. CAPSA, Capsazepine $(10 \mathrm{mg} / \mathrm{kg})$.

obviating the need to use a higher dose at that this time point. In the late phase, higher doses of this compound were not investigated because the neuroprotective effect of AEA in this phase is blocked by SR141716A.

These data might suggest that the SR141716A-insensitive, early neuroprotective effect observed previously with AEA in the same in vivo model (van der Stelt et al., 2001b) may have been attributable to the formation of 12-HAEA and 15-HAEA. To test this hypothesis, the nonselective lipoxygenase inhibitor NDGA was injected $5 \mathrm{~min}$ before AEA. NDGA did not reverse the AEAinduced reduction in lesion volume (Figs. $2 A, 3$ ). In contrast, pretreatment of NDGA enhanced the neuroprotective effect of AEA $(p<0.05)$ (Figs. $2 A, 3)$, resulting in a $51 \%$ smaller lesion volume compared with control animals $(p<0.05)$ (Figs. $2 A, 3)$.

\section{Effects of $\mathrm{VR}_{1}$ modulation on}

\section{ouabain-induced neurodegeneration}

To investigate the possible involvement of $\mathrm{VR}_{1}$ in AEA-induced neuroprotection, we performed three types of experiments. First, we tested the neuroprotective effect of arvanil, a synthetic AEA analog, which is metabolically more stable than AEA and activates both $\mathrm{CB}_{1}$ and, more potently, $\mathrm{VR}_{1}$ receptors but not $\mathrm{CB}_{2}$ receptors (Melck et al., 1999; Di Marzo et al., 2001b). Next, we tested the effect of capsaicin, a selective $\mathrm{VR}_{1}$ agonist. And finally, we tested the effect of the $\mathrm{VR}_{1}$ antagonist capsazepine on AEAinduced neuroprotection.

Unlike THC, AEA, and 12-HAEA, arvanil (1 mg/kg) did not reduce lesion size on DW-MRI in the acute phase after injection of ouabain (38 $\pm 4.2 \mathrm{~mm}^{3} ; p \gg 0.05$ vs control) (data not shown), although it was dose-dependently effective at $7 \mathrm{~d}$ (Figs. 4,
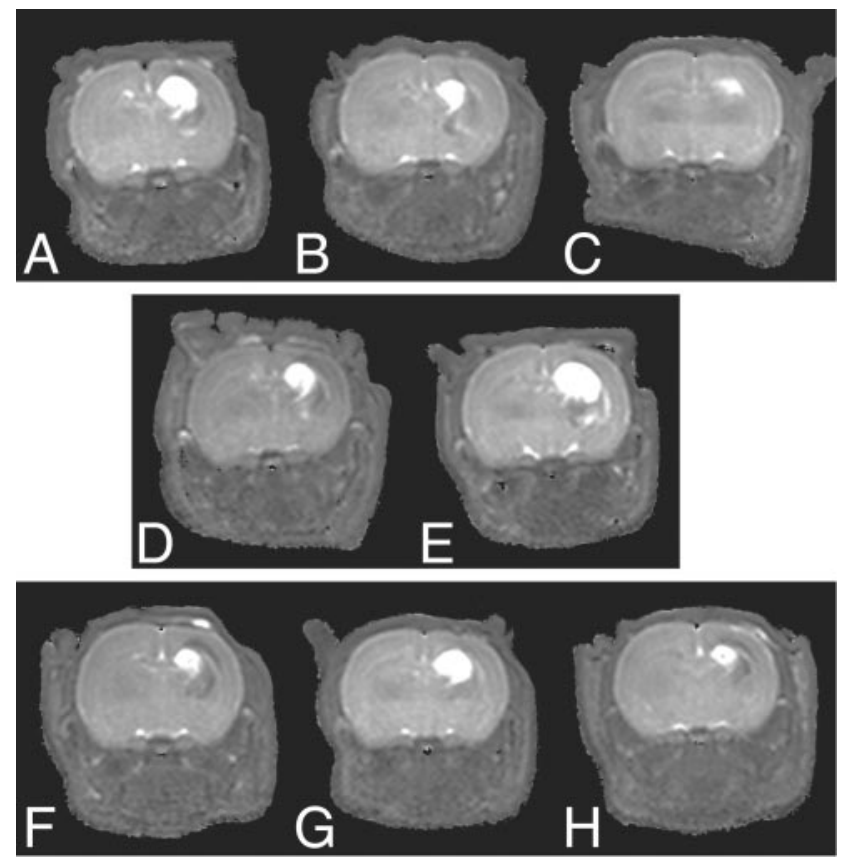

Figure 4. Typical parametric $\mathrm{T}_{2}$ maps calculated from $\mathrm{T}_{2}$-weighted MRI data acquired $7 \mathrm{~d}$ after injection of ouabain. The treatments are as follows: $A$, vehicle; $B$, arvanil $(0.1 \mathrm{mg} / \mathrm{kg}) ; C$, arvanil (1 mg/kg); $D$, arvanil (1 mg/kg) plus SR141716A (1 mg/kg); $E$, arvanil $(1 \mathrm{mg} / \mathrm{kg})$ plus SR141716A (3 mg/kg); $F$, arvanil (1 mg/kg) plus capsazepine $(5 \mathrm{mg} / \mathrm{kg}) ; G$, arvanil $(1 \mathrm{mg} / \mathrm{kg})$ plus capsazepine $(10 \mathrm{mg} / \mathrm{kg})$; and $H$, capsaicin $(1 \mathrm{mg} / \mathrm{kg})$.

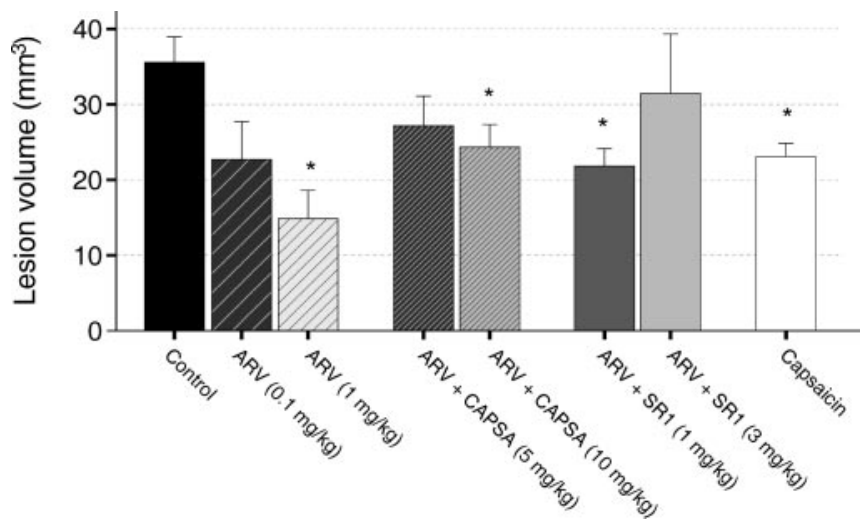

Figure 5. Lesion volumes as determined from $\mathrm{T}_{2}$ maps acquired $7 \mathrm{~d}$ after ouabain injection. Error bars represent means $\pm S E$. ${ }^{*} p<0.05$ versus control. See legend to Figure 4 for all of the doses. ARV, Arvanil; CAPSA, capsazepine; SR1, SR141716A.

5). This effect was mimicked by capsaicin at $1 \mathrm{mg} / \mathrm{kg}$. Noteworthy, arvanil was more potent than AEA, capsaicin, and THC after $7 \mathrm{~d}$. The $1 \mathrm{mg} / \mathrm{kg}$ dose was the highest tolerated dose of capsaicin for neonatal animals. With arvanil, previous data in adult rats (Di Marzo et al., 2001a) and mice (Di Marzo et al., 2000), obtained after intraperitoneal or intravenous administrations of $10 \mathrm{mg} / \mathrm{kg}$ of the substance, respectively, showed that arvanil is much better tolerated and less toxic than capsaicin (whose highest tolerated dose was $1 \mathrm{mg} / \mathrm{kg}$ in both cases).

To investigate which receptor between $\mathrm{CB}_{1}$ and $\mathrm{VR}_{1}$ mediates arvanil-induced neuroprotection in the late phase, the $\mathrm{CB}_{1}$ receptor antagonist SR141716A or the $\mathrm{VR}_{1}$ antagonist capsazepine were coinjected with arvanil $(1 \mathrm{mg} / \mathrm{kg})$ into neonatal rats. SR141716A dose-dependently reduced the neuroprotective effect of arvanil, suggesting the involvement of $\mathrm{CB}_{1}$ receptors. Interest- 
ingly, capsazepine was also able to reduce the effect of arvanil, indicating the possible involvement of $\mathrm{VR}_{1}$ (Figs. 4, 5). Capsazepine at $10 \mathrm{mg} / \mathrm{kg}$ did not completely block the effect of arvanil, but higher doses could not be tested because of the limited solubility of capsazepine in the vehicle solution. However, this dose of the antagonist was shown previously to be sufficient to entirely block capsaicin-induced $(1 \mathrm{mg} / \mathrm{kg}$ ) hypolocomotor effects in adult rats but has no effect on movement impairment induced by arvanil (1 mg/kg) (Di Marzo et al., 2001a). The finding that arvanil and capsaicin were able to attenuate ouabain-induced neurodegeneration in neonatal rats in a capsazepine-dependent manner suggests that $\mathrm{VR}_{1}$ stimulation can afford neuroprotection in this in vivo model. To test whether $\mathrm{VR}_{1}$ could also be involved in the neuroprotective effects of AEA, capsazepine $(10 \mathrm{mg} / \mathrm{kg})$ was coinjected with AEA $(10 \mathrm{mg} / \mathrm{kg})$. However, capsazepine was unable to block the neuroprotective effect of AEA in both the acute and the late phase (Figs. 2, 3), arguing against a $\mathrm{VR}_{1}$-mediated mechanism for AEA. Importantly, $\mathrm{VR}_{1}$ antagonism by capsazepine (10 $\mathrm{mg} / \mathrm{kg}$ ) alone also reduced brain injury at $7 \mathrm{~d}$ (Figs. 2, 3).

\section{Discussion}

The endocannabinoid system is likely to be exploited for the development of therapeutics against acute neurodegeneration ( $\mathrm{Na}$ gayama et al., 1999; Panikashvili et al., 2001; van der Stelt et al., 2001b) (for review, see van der Stelt et al., 2002a). AEA affords neuroprotection, both in vitro and in vivo, which is only in part mediated by the $\mathrm{CB}_{1}$ receptor (Sinor et al., 2000; van der Stelt et al., 2001b). This suggests that other targets of AEA or its metabolites may contribute to the observed effects in vivo. In this study, we assessed a possible role for $\mathrm{VR}_{1}$ and/or lipoxygenase metabolism in the neuroprotection induced by AEA against ouabaininduced in vivo excitotoxicity. The main findings are as follows: (1) the 12-lipoxygenase metabolite of AEA, 12-HAEA, attenuated cytotoxic edema in a $\mathrm{CB}_{1}$ receptor-independent manner in the acute phase after ouabain injection; (2) the 15-lipoxygenase metabolite, 15-HAEA, enhanced the neuroprotective effect of AEA in the acute phase; (3) modulation of $\mathrm{VR}_{1}$ leads to neuroprotective effects in our model, and arvanil is a potent neuroprotectant, acting at both cannabinoid and vanilloid receptors; and (4) the acute in vivo neuroprotective effects of AEA are not mediated by either lipoxygenase metabolism or $\mathrm{VR}_{1}$.

\section{Neuroprotection by lipoxygenase products of anandamide}

We showed that rat blood and perfused (blood-free) rat brain convert exogenous AEA into 12-HAEA and 15-HAEA in an NDGA-sensitive manner. Our findings are in line with previous studies using rat brain (Miyamoto et al., 1987) or human blood (Edgemond et al., 1998). Endogenous lipoxygenase metabolites of AEA have never been detected, but recent data suggest that they may mediate some of the actions ascribed to AEA (Kagaya et al., 2002). For example, the $\mathrm{VR}_{1}$-mediated contractile action of AEA in guinea pig bronchus may be attributable, at least in part, to some of its oxygenated metabolites (Craib et al., 2001). Here, we showed that 12-HAEA was able to mimic the AEA-induced reduction of cytotoxic edema in the acute phase after ouabain injection, in a $\mathrm{CB}_{1}$-independent manner. The 12-HAEA-induced reduction in cellular swelling is likely to occur also independently of the activation of $\mathrm{VR}_{1}$, because 12-HAEA, unlike its hydroperoxy homolog, is not an agonist at $\mathrm{VR}_{1}$ (Hwang et al., 2000). Furthermore, $\mathrm{VR}_{1}$-stimulation by arvanil did not mimic the reduction of cellular swelling in the early phase (see below). 15HAEA was able to enhance the neuroprotective effect of AEA. Because 15-HAEA has been shown to competitively inhibit the hydrolysis of AEA by FAAH (van der Stelt et al., 2002b), an "entourage" effect might be responsible for the neuroprotection afforded by this compound (for a definition of "entourage" effect, see Mechoulam et al., 1998). However, neither 12-HAEA nor 15HAEA afforded long-lasting protection in our model, although, in contrast to the effect of 12-HAEA, the effect of 15-HAEA almost reached significance also on day $7(p=0.07)$ (Figs. 2, 3).

At the moment, it is not clear which molecular targets are responsible for the observed effects of 12-HAEA in the acute phase. However, pretreatment with the nonselective lipoxygenase inhibitor NDGA did not reverse the AEA-induced reduction in cytotoxic edema (Fig. 2), and, in contrast, it enhanced the effect of AEA $(p<0.05)$. These results indicate that in vivo metabolism catalyzed by lipoxygenases, either directly on AEA or on AA produced from its hydrolysis (Willoughby et al., 1997; Adams et al., 1998), is unlikely to contribute to the AEA-induced reduction of cytotoxic edema. Indeed, application of NDGA alone also reduced the volume of cytotoxic edema by $25 \%(p<0.05)$ (Fig. 2 ). This may indicate that endogenous lipoxygenase activity contributes to the neurotoxic events, although an alternative explanation might be that NDGA exerts its protective actions via nonspecific antioxidant activity (Shishido et al., 2001). Altogether, these data indicate that endogenous lipoxygenase activity does not contribute to the neuroprotective actions of AEA.

\section{Role of $\mathrm{VR}_{1}$ modulation in neuroprotection by AEA and arvanil}

$\mathrm{VR}_{1}$ is a ligand-gated nonselective cation channel, activation of which results in nonselective cation influx, $\mathrm{Ca}^{2+}$ influx, membrane depolarization, and glutamate release (Szallasi and Blumberg, 1999). During acute neurodegenerative insults, such as ischemia or trauma, these mechanisms are likely to be detrimental. In fact, capsaicin treatment is sometimes used to degenerate peripheral nerves. However, $\mathrm{VR}_{1}$ is easily desensitized by its agonists, and desensitization might lead to neuroprotection if $\mathrm{VR}_{1}$ contributes in any way to the neuronal injury during excitotoxicity. In fact, capsaicin, the prototypic $\mathrm{VR}_{1}$ agonist, has been shown previously to inhibit Tween 80 -induced convulsions in vivo (Dib and Falchi, 1996). We report here for the first time a dose-dependent protection afforded by a hybrid $\mathrm{CB}_{1} / \mathrm{VR}_{1}$ ligand, arvanil, and by capsaicin. The neuroprotective effect of arvanil was mediated by activation of both $\mathrm{CB}_{1}$ and $\mathrm{VR}_{1}$ receptors and was more potent than that of capsaicin, AEA, and THC. The higher efficacy of arvanil may be attributable to a synergistic action on two signaling pathways, i.e., (1) stimulation of the $\mathrm{CB}_{1}$ receptor and (2) rapid desensitization of $\mathrm{VR}_{1}$, which might lead to a reduction in calcium influx and glutamate release. The latter, tentative mechanism is supported by the following data. (1) $\mathrm{VR}_{1}$ is present in the CNS (Mezey et al., 2000; Sanchez et al., 2001; Szabo et al., 2002), including in the striatum (Hajos et al., 1988). (2) In the PNS, desensitization is a standard response of $\mathrm{VR}_{1}$ to stimulation by exogenously administered agonists (Szallasi and Blumberg, 1999; Sanchez et al., 2001). Desensitization is known to take place on time scales relevant to the current experiments [e.g., within $30 \mathrm{~min}$ in sensory nerve terminals of guinea pigs (Maggi, 1995) or in the rat heart (McLean et al., 2002)]. (3) Although little is known about the pharmacology of $\mathrm{VR}_{1}$ in the brain, preliminary observations of repeated capsaicin injections showed that capsaicin-induced stimulation of CNS neurons could be blocked by capsaicin pretreatment, suggesting that desensitization may also occur centrally (Hajos et al., 1987). (4) Desensitization by agonists is prevented by the simultaneous presence of an antagonist (Jung et al., 1998, 1999; Liu et al., 2001), 
a phenomenon also observed in our study after cotreatment of arvanil with capsazepine. (5) In the current study, blocking $\mathrm{VR}_{1}$ using capsazepine also afforded protection. Thus, we propose that both $\mathrm{CB} 1$ activation and $\mathrm{VR}_{1}$ desensitization may have contributed to the effect of arvanil. Interestingly, similar results have been reported previously for the cytostatic treatment of human breast cancer cells. In those experiments, the effect of AEA was mediated via $\mathrm{CB}_{1}$ receptors, whereas arvanil exerted a more potent effect that was antagonized by both SR141716A and capsazepine (Melck et al., 1999).

$\mathrm{VR}_{1}$ activation is unlikely to be deleterious to the CNS in general, but we argue that this might be the case in a setting of CNS injury. For example, in ischemia, the inflammatory mediator bradykinin and the prototypic proinflammatory cytokine tumor necrosis factor- $\alpha$ may sensitize $\mathrm{VR}_{1}$ (Nicol et al., 1997; Shin et al., 2002; Sugiura et al., 2002). Sensitization of $\mathrm{VR}_{1}$ by ligand binding, mildly acidic $\mathrm{pH}$, or inflammatory mediators may result in activation of the receptor by temperatures well within the physiologic range (Tominaga et al., 1998; Vyklicky et al., 1998). Additionally, $\mathrm{VR}_{1}$ stimulation results in release of substance $\mathrm{P}$, which is a proinflammatory neuropeptide (Martin et al., 1992; Annunziata et al., 2002). If these conditions occur during ouabain-induced excitotoxicity, $\mathrm{VR}_{1}$ desensitization by capsaicin and arvanil or $\mathrm{VR}_{1}$ antagonism by capsazepine may explain the neuroprotective effects of these substances.

However, we cannot exclude the possibility that other mechanisms may have contributed to the protection afforded by arvanil, capsaicin, or capsazepine. For example, both capsaicin and its dihydroderivate nordihydrocapsiate have similar, potent antiinflammatory properties in vivo via nuclear factor- $\kappa \mathrm{B}$ inhibition, possibly via a non-VR $\mathrm{VR}_{1}$-mediated mechanism (Sancho et al., 2002). Furthermore, capsaicin has been shown to stimulate the biosynthesis of endocannabinoids (Di Marzo et al., 2001a), which may afford neuroprotection. Alternatively, the presence in the $\mathrm{CNS}$ of as yet undefined $\mathrm{CB}_{\mathrm{n}}$ receptors, sensitive to capsaicin, capsazepine, SR141716A, arvanil, and AEA has been suggested (Brooks et al., 2002; Hajos and Freund, 2002), which might play a role in arvanil-mediated neuroprotection.

In our model, we observed non- $\mathrm{CB}_{1}$-dependent effects of AEA directly after ouabain injection and $\mathrm{CB}_{1}$-dependent effects after $7 \mathrm{~d}$. In contrast, the neuroprotection by arvanil was evident at $7 \mathrm{~d}$ and was not manifested by a reduction in cytotoxic edema in the acute phase. These observations, as well as the finding that the action of AEA was not counteracted by capsazepine, used at a dose that was effective against a much more potent $\mathrm{VR}_{1}$ agonist (arvanil), strongly suggest that the neuroprotective effects of the endocannabinoid are not attributable to $\mathrm{VR}_{1}$ stimulation. Therefore, it can be concluded that, although the late effect of AEA is entirely mediated by $\mathrm{CB}_{1}$ receptors, the early action of this compound is attributable to a mechanism yet to be identified.

\section{Conclusions}

AEA protects rat brain from ouabain-induced excitotoxicity. This effect is inhibited by $\mathrm{CB}_{1}$ but not $\mathrm{VR}_{1}$ antagonists and is not mediated by lipoxygenase metabolites. Arvanil is more potent than $\mathrm{AEA}$, and both $\mathrm{CB}_{1}$ and $\mathrm{VR}_{1}$ are involved in neuroprotection after arvanil treatment. We suggest that both $\mathrm{VR}_{1}$ and $\mathrm{CB}_{1}$ receptors might be valuable targets for therapy and drug discovery in protection against brain injury and that arvanil represents a promising subject for future studies aiming at developing a monotherapy that targets both receptors simultaneously.

\section{References}

Adams IB, Compton DR, Martin BR (1998) Assessment of anandamide interaction with the cannabinoid brain receptor: SR 141716A antagonism studies in mice and autoradiographic analysis of receptor binding in rat brain. J Pharmacol Exp Ther 284:1209-1217.

Annunziata P, Cioni C, Santonini R, Paccagnini E (2002) Substance P antagonist block leakage and reduces activation of cytokine-stimulated rat brain endothelium. J Neuroimmunol 131:41-49.

Bayewitch M, Avidor-Reiss T, Levy R, Barg J, Mechoulam R, Vogel Z (1995) The peripheral cannabinoid receptor: adenylate cyclase inhibition and G protein coupling. FEBS Lett 375:143-147.

Bligh E, Dyer W (1959) A rapid method of total lipid extraction and purification. Can J Biochem Physiol 37:911-920.

Brooks JW, Pryce G, Bisogno T, Jaggar SI, Hankey DJ, Brown P, Bridges D, Ledent C, Bifulco M, Rice AS, Di Marzo V, Baker D (2002) Arvanilinduced inhibition of spasticity and persistent pain: evidence for therapeutic sites of action different from the vanilloid VR1 receptor and cannabinoid $\mathrm{CB}(1) / \mathrm{CB}(2)$ receptors. Eur J Pharmacol 439:83-92.

Craib SJ, Ellington HC, Pertwee RG, Ross RA (2001) A possible role of lipoxygenase in the activation of vanilloid receptors by anandamide in the guinea-pig bronchus. Br J Pharmacol 134:30-37.

de Graaf RA, Braun KP, Nicolay K (2001) Single-shot diffusion trace (1)HNMR spectroscopy. Magn Reson Med 45:741-748.

Devane WA, Hanus L, Breuer A, Pertwee RG, Stevenson LA, Griffin G, Gibson D, Mandelbaum A, Etinger A, Mechoulam R (1992) Isolation and structure of a brain constituent that binds to the cannabinoid receptor. Science 258:1946-1949.

Di Marzo V, Melck D, Bisogno T, De Petrocellis L (1998) Endocannabinoids: endogenous cannabinoid receptor ligands with neuromodulatory action. Trends Neurosci 21:521-528.

Di Marzo V, Breivogel C, Bisogno T, Melck D, Patrick G, Tao Q, Szallasi A, Razdan RK, Martin BR (2000) Neurobehavioral activity in mice of $\mathrm{N}$-vanillyl-arachidonyl-amide. Eur J Pharmacol 406:363-374.

Di Marzo V, Lastres-Becker I, Bisogno T, De Petrocellis L, Milone A, Davis JB, Fernandez-Ruiz JJ (2001a) Hypolocomotor effects in rats of capsaicin and two long chain capsaicin homologues. Eur J Pharmacol 420:123-131.

Di Marzo V, Bisogno T, De Petrocellis L, Brandi I, Jefferson RG, Winckler RL, Davis JB, Dasse O, Mahadevan A, Razdan RK, Martin BR (2001b) Highly selective $\mathrm{CB}(1)$ cannabinoid receptor ligands and novel $\mathrm{CB}(1) /$ VR(1) vanilloid receptor "hybrid" ligands. Biochem Biophys Res Commun 281:444-451.

Di Marzo V, Griffin G, De Petrocellis L, Brandi I, Bisogno T, Williams W, Grier MC, Kulasegram S, Mahadevan A, Razdan RK, Martin BR (2002) A structure/activity relationship study on arvanil, an endocannabinoid and vanilloid hybrid. J Pharmacol Exp Ther 300:984-991.

Dib B, Falchi M (1996) Convulsions and death induced in rats by Tween 80 are prevented by capsaicin. Int J Tissue React 18:27-31.

Edgemond WS, Hillard CJ, Falck JR, Kearn CS, Campbell WB (1998) Human platelets and polymorphonuclear leukocytes synthesize oxygenated derivatives of arachidonylethanolamide (anandamide): their affinities for cannabinoid receptors and pathways of inactivation. Mol Pharmacol 54:180-188.

Gonsiorek W, Lunn C, Fan X, Narula S, Lundell D, Hipkin RW (2000) Endocannabinoid 2-arachidonyl glycerol is a full agonist through human type 2 cannabinoid receptor: antagonism by anandamide. Mol Pharmacol 57:1045-1050.

Hajos N, Freund T (2002) Pharmacological separation of cannabinoid sensitive receptors on hippocampal excitatory and inhibitory fibers. Neuropharmacology 43:503-510.

Hajos M, Jancso G, Engberg G (1987) Capsaicin-induced excitation of locus coeruleus neurons. Acta Physiol Scand 129:415-420.

Hajos M, Engberg G, Nissbrandt H, Magnusson T, Carlsson A (1988) Capsaicin-sensitive vasodilatatory mechanisms in the rat substantia nigra and striatum. J Neural Transm 74:129-139.

Huang SM, Bisogno T, Trevisani M, Al-Hayani A, De Petrocellis L, Fezza F, Tognetto M, Petros TJ, Krey JF, Chu CJ, Miller JD, Davies SN, Geppetti P, Walker JM, Di Marzo V (2002) An endogenous capsaicin-like substance with high potency at recombinant and native vanilloid VR1 receptors. Proc Natl Acad Sci USA 99:8400-8405.

Hwang SW, Cho H, Kwak J, Lee SY, Kang CJ, Jung J, Cho S, Min KH, Suh YG, Kim D, Oh U (2000) Direct activation of capsaicin receptors by prod- 
ucts of lipoxygenases: endogenous capsaicin-like substances. Proc Natl Acad Sci USA 97:6155-6160.

Jung YS, Cho TS, Moon CH, Shin HS (1998) Capsaicin-induced desensitization is prevented by capsazepine but not by ruthenium red in guinea pig bronchi. Eur J Pharmacol 362:193-198.

Jung YS, Cho TS, Moon CH, Lee B, Lee SM, Shin HS (1999) Systemically administered capsazepine prevents the capsaicin-induced functional desensitization and loss of substance P-like immunoreactivity (SP-LI) in guinea-pig bronchi. Life Sci 64:PL173-PL177.

Kagaya M, Lamb J, Robbins J, Page CP, Spina D (2002) Characterization of the anandamide induced depolarization of guinea-pig isolated vagus nerve. Br J Pharmacol 137:39-48.

Liu L, Oortgiesen M, Li L, Simon SA (2001) Capsaicin inhibits activation of voltage-gated sodium currents in capsaicin-sensitive trigeminal ganglion neurons. J Neurophysiol 85:745-758.

Maggi CA (1995) Tachykinins and calcitonin gene-related peptide (CGRP) as co-transmitters released from peripheral endings of sensory nerves. Prog Neurobiol 45:1-98.

Marinelli S, Vaughan CW, Christie MJ, Connor M (2002) Capsaicin activation of glutamatergic synaptic transmission in the rat locus coeruleus in vitro. J Physiol (Lond) 543:531-540.

Martin FC, Charles AC, Sanderson MJ, Merrill JE (1992) Substance P stimulates IL-1 production by astrocytes via intracellular calcium. Brain Res 599:13-18.

McLean PG, Aston D, Sarkar D, Ahluwalia A (2002) Protease-activated receptor-2 activation causes EDHF-like coronary vasodilation: selective preservation in ischemia/reperfusion injury: involvement of lipoxygenase products, VR1 receptors, and C-fibers. Circ Res 90:465-472.

Mechoulam R, Ben-Shabat S, Hanus L, Ligumsky M, Kaminski NE, Schatz AR, Gopher A, Almog S, Martin BR, Compton DR (1995) Identification of an endogenous 2-monoglyceride, present in canine gut, that binds to cannabinoid receptors. Biochem Pharmacol 50:83-90.

Mechoulam R, Fride E, Di Marzo V (1998) Endocannabinoids. Eur J Pharmacol 359:1-18.

Mechoulam R, Spatz M, Shohami E (2002) Endocannabinoids and neuroprotection. Sci STKE 2002:RE5.

Melck D, Bisogno T, De Petrocellis L, Chuang H, Julius D, Bifulco M, Di Marzo V (1999) Unsaturated long-chain $N$-acyl-vanillyl-amides ( $N$ AVAMs): vanilloid receptor ligands that inhibit anandamide-facilitated transport and bind to CB1 cannabinoid receptors. Biochem Biophys Res Commun 262:275-284.

Mezey E, Toth ZE, Cortright DN, Arzubi MK, Krause JE, Elde R, Guo A, Blumberg PM, Szallasi A (2000) Distribution of mRNA for vanilloid receptor subtype 1 (VR1), and VR1-like immunoreactivity, in the central nervous system of the rat and human. Proc Natl Acad Sci USA 97:3655-3660.

Miyamoto T, Lindgren JA, Samuelsson B (1987) Isolation and identification of lipoxygenase products from the rat central nervous system. Biochim Biophys Acta 922:372-378.

Nagayama T, Sinor AD, Simon RP, Chen J, Graham SH, Jin K, Greenberg DA (1999) Cannabinoids and neuroprotection in global and focal cerebral ischemia and in neuronal cultures. J Neurosci 19:2987-2995.

Nicol GD, Lopshire JC, Pafford CM (1997) Tumor necrosis factor enhances the capsaicin sensitivity of rat sensory neurons. J Neurosci 17:975-982.

Panikashvili D, Simeonidou C, Ben-Shabat S, Hanus L, Breuer A, Mechoulam $\mathrm{R}$, Shohami E (2001) An endogenous cannabinoid (2-AG) is neuroprotective after brain injury. Nature 413:527-531.

Parmentier-Batteur S, Jin K, Mao XO, Xie L, Greenberg DA (2002) Increased severity of stroke in $\mathrm{CB} 1$ cannabinoid receptor knock-out mice. J Neurosci 22:9771-9775.

Sanchez JF, Krause JE, Cortright DN (2001) The distribution and regulation of vanilloid receptor VR1 and VR1 5' splice variant RNA expression in rat. Neuroscience 107:373-381.
Sancho R, Lucena C, Macho A, Calzado MA, Blanco-Molina M, Minassi A, Appendino G, Munoz E (2002) Immunosuppressive activity of capsaicinoids: capsiate derived from sweet peppers inhibits NF-kappaB activation and is a potent antiinflammatory compound in vivo. Eur J Immunol 32:1753-1763.

Shin J, Cho H, Hwang SW, Jung J, Shin CY, Lee SY, Kim SH, Lee MG, Choi YH, Kim J, Haber NA, Reichling DB, Khasar S, Levine JD, Oh U (2002) Bradykinin-12-lipoxygenase-VR1 signaling pathway for inflammatory hyperalgesia. Proc Natl Acad Sci USA 99:10150-10155.

Shishido Y, Furushiro M, Hashimoto S, Yokokura T (2001) Effect of nordihydroguaiaretic acid on behavioral impairment and neuronal cell death after forebrain ischemia. Pharmacol Biochem Behav 69:469-474.

Sinor AD, Irvin SM, Greenberg DA (2000) Endocannabinoids protect cerebral cortical neurons from in vitro ischemia in rats. Neurosci Lett 278:157-160.

Smart D, Gunthorpe MJ, Jerman JC, Nasir S, Gray J, Muir AI, Chambers JK, Randall AD, Davis JB (2000) The endogenous lipid anandamide is a full agonist at the human vanilloid receptor (hVR1). Br J Pharmacol 129:227-230.

Sugiura T, Tominaga M, Katsuya H, Mizumura K (2002) Bradykinin lowers the threshold temperature for heat activation of vanilloid receptor 1 . J Neurophysiol 88:544-548.

Szabo T, Biro T, Gonzalez AF, Palkovits M, Blumberg PM (2002) Pharmacological characterization of vanilloid receptor located in the brain. Brain Res Mol Brain Res 98:51-57.

Szallasi A, Blumberg PM (1999) Vanilloid (Capsaicin) receptors and mechanisms. Pharmacol Rev 51:159-212.

Tominaga M, Caterina MJ, Malmberg AB, Rosen TA, Gilbert H, Skinner K, Raumann BE, Basbaum AI, Julius D (1998) The cloned capsaicin receptor integrates multiple pain-producing stimuli. Neuron 21:531-543.

van der Stelt M, Veldhuis WB, Bar PR, Veldink GA, Vliegenthart JF, Nicolay K (2001a) Neuroprotection by $\Delta 9$-tetrahydrocannabinol, the main active compound in marijuana, against ouabain-induced in vivo excitotoxicity. J Neurosci 21:6475-6479.

van der Stelt M, Veldhuis WB, van Haaften GW, Fezza F, Bisogno T, Bar PR, Veldink GA, Vliegenthart JF, Di Marzo V, Nicolay K (2001b) Exogenous anandamide protects rat brain against acute neuronal injury in vivo. J Neurosci 21:8765-8771.

van der Stelt M, Veldhuis WB, Maccarrone M, Bar PR, Nicolay K, Veldink GA, Di Marzo V, Vliegenthart JF (2002a) Acute neuronal injury, excitotoxicity, and the endocannabinoid system. Mol Neurobiol 26:317-346.

van der Stelt M, van Kuik JA, Bari M, van Zadelhoff G, Leeflang BR, Veldink GA, Finazzi-Agro A, Vliegenthart JF, Maccarrone M (2002b) Oxygenated metabolites of anandamide and 2-arachidonoylglycerol: conformational analysis and interaction with cannabinoid receptors, membrane transporter, and fatty acid amide hydrolase. J Med Chem 45:3709-3720.

van Zadelhoff G, Veldink GA, Vliegenthart JF (1998) With anandamide as substrate plant 5-lipoxygenases behave like 11-lipoxygenases. Biochem Biophys Res Commun 248:33-38.

Veldhuis WB, van der Stelt M, Delmas F, Gillet B, Veldink GA, Vliegenthart JF, Nicolay K, Bär PR (2003) In vivo excitotoxicity induced by ouabain, a Na ${ }^{+} / \mathrm{K}^{+}$-ATPase inhibitor. J Cereb Blood Flow Metab 23:62-74.

Vyklicky L, Knotkova-Urbancova H, Vitaskova Z, Vlachova V, Kress M, Reeh PW (1998) Inflammatory mediators at acidic $\mathrm{pH}$ activate capsaicin receptors in cultured sensory neurons from newborn rats. J Neurophysiol 79:670-676.

Willoughby KA, Moore SF, Martin BR, Ellis EF (1997) The biodisposition and metabolism of anandamide in mice. J Pharmacol Exp Ther 282:243-247.

Zygmunt PM, Petersson J, Andersson DA, Chuang H, Sorgard M, Di Marzo V, Julius D, Hogestatt ED (1999) Vanilloid receptors on sensory nerves mediate the vasodilator action of anandamide. Nature 400:452-457. 